\author{
Military Technical College \\ Kobry Elkobbah, \\ Cairo, Egypt \\ May 27-29,2008
}

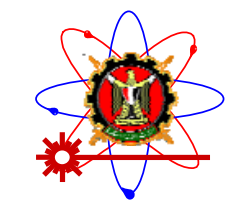
$4^{\text {th }}$ International Conference on
Mathematics and Engineering
Physics (ICMEP-4)

\title{
PH-1
}

\section{Application of Gabbor Hologram for Designing a New Optical Imaging System}

\author{
M.Darwish $^{1}$, Ashraf F. El Sherif ${ }^{2}$, and Hatem El Ghandoor ${ }^{3}$
}

\begin{abstract}
Since most optical imaging system depends on tracking surface detail, a key discovery was that most modern laminated work surfaces are microscopically embossed, presumably to reduce glare. When this texture is obliquely illuminated by a light source a pattern of highlights and shadows (speckle pattern) is revealed. The performance of the optical imaging systems with different diffuse has been studied. It is important for accurate study to know the characteristics of these surfaces produced by Gabbor holography technique.

Single-exposure Gabbor holograms using different types of light sources (i.e. He-Ne laser, diode laser, various color LEDs), diffusers, and holographic plates is presented. Circular interference fringes from single-exposure Gabbor hologram were recorded.

Relations between the squared radii of the fringes and their interference order for each light source were presented to calculate the wavelengths of diode laser, various color LEDs,. The measured wavelengths were found to be in good agreement with the real one. So, we can differentiate between all of these diffusers for designing a new optical imaging system based on the laser speckle pattern.
\end{abstract}

\section{Introduction:}

Gabbor hologram was obtained by making single exposure using the experimental set-up shown in fig.1. The system consists of a diffuser $\mathrm{D}$, which is illuminated by laser collimated beam. Part of the incident light goes through $\mathrm{D}$ without being scattered, and the rest is scattered by the grains of the speckle recorded on $\mathrm{D}$. The holographic plate $\mathrm{H}$ can be placed at any arbitrary distance $\mathrm{L}$ from the diffuser D. In this experiment the reference beam is the unscattered beam [1].

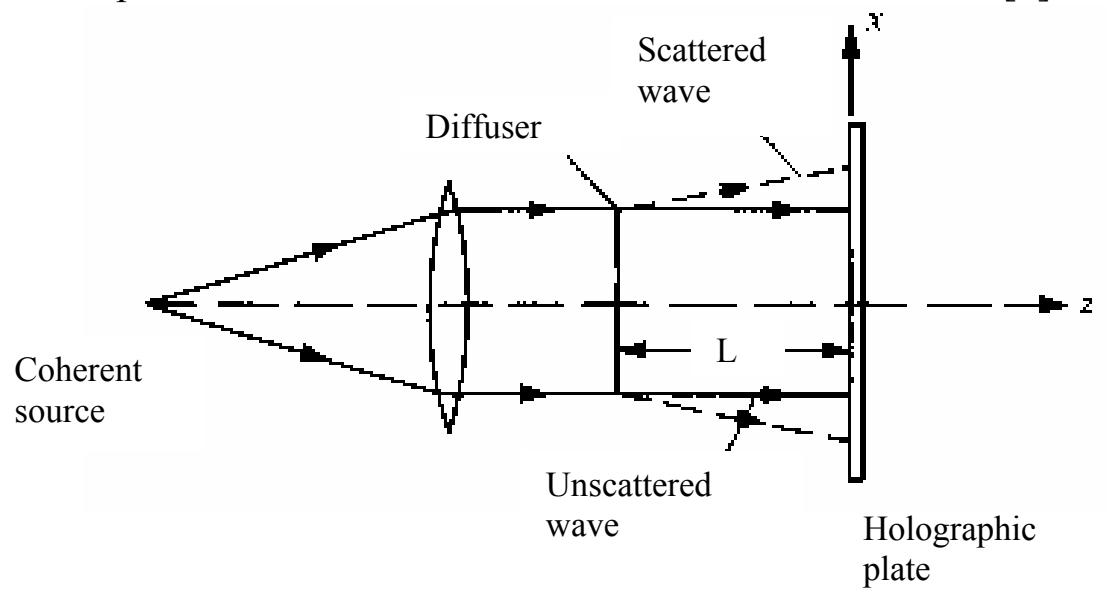

Fig. 1 Recording of Gabbor hologram due to interference of scattered and unscattered coherent waves through the diffuser D. 
Illuminating the hologram $\mathrm{H}$ by a parallel beam of light, two identical and symmetrical diffusers are reconstructed as shown in fig.2 in the form of virtual image D" and, a real image D'.

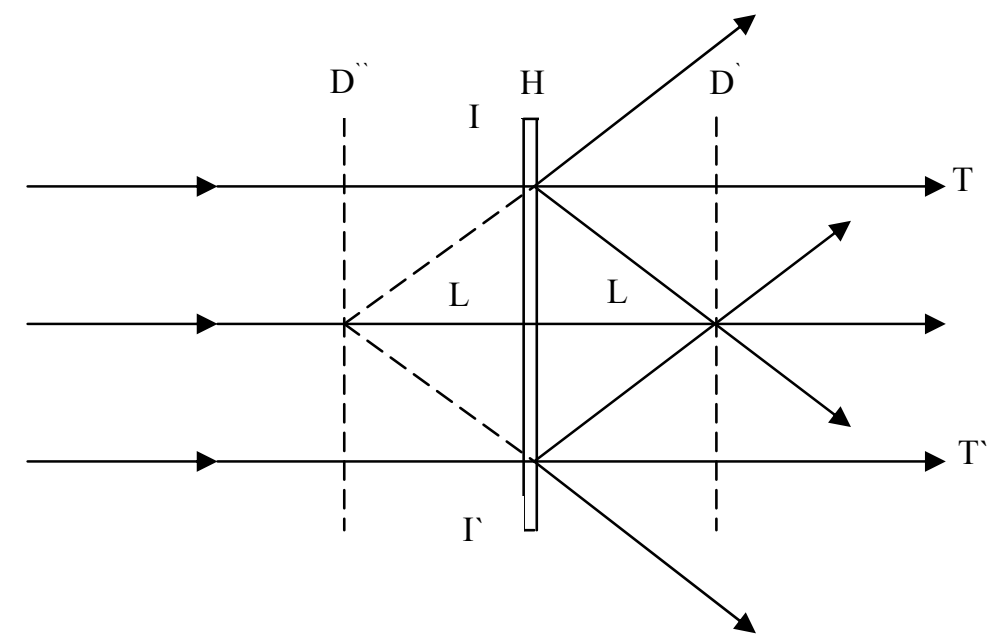

Fig. 2 Reconstruction of images D' and D" of the diffuser D from the hologram H.

These two images produce circular fringes localized at infinity due to interference with a phase difference $\delta \varphi$ given by:

$$
\delta \varphi=\frac{\pi}{\lambda} * \frac{R_{k}^{2}}{f^{2}}(2 L)
$$

Since D" and D' are separated by distance $2 \mathrm{~L}$ and $\mathrm{R}_{\mathrm{k}}$ is the radius of the fringe of order $\mathrm{K}$. For bright fringes $\delta \varphi=2 \pi K$ consequently,

$$
\frac{\pi}{\lambda} * \frac{R_{k}^{2}}{f^{2}}(2 L)=2 \pi K
$$

Then, the ring radius is related to the interference order $\mathrm{K}$, wavelength $\lambda$ and the focal length $\mathrm{f}$ through the equation:

$$
R_{k}^{2}=\frac{k \lambda f^{2}}{L}
$$

For two successive bright fringes we have:

$$
R_{k+1}^{2}-R_{k}^{2}=\frac{\lambda f^{2}}{L}
$$

\section{Experimental work:}

\subsection{Production of diffuse Object:}

The scattering plates, or diffusers, which are used in the following experiments, are obtained in the form of speckle patterns. These patterns are recorded photographically making use of the set-up shown in fig.3. In the experiment a laser beam is allowed to diverge by means of a microscope objective $\mathrm{O}$ in order to cover the area of the ground glass G. Let the area of the ground glass $\mathrm{G}$ be limited through a circular aperture $\mathrm{T}$ of diameter $2 \mathrm{a}$ which is smaller than the distance $\mathrm{L}$ between the ground glass $\mathrm{G}$ and the photographic plate $\mathrm{H}$. the plate $\mathrm{G}$ is supposed to consists of many independent scattering points of random phases and amplitudes. 


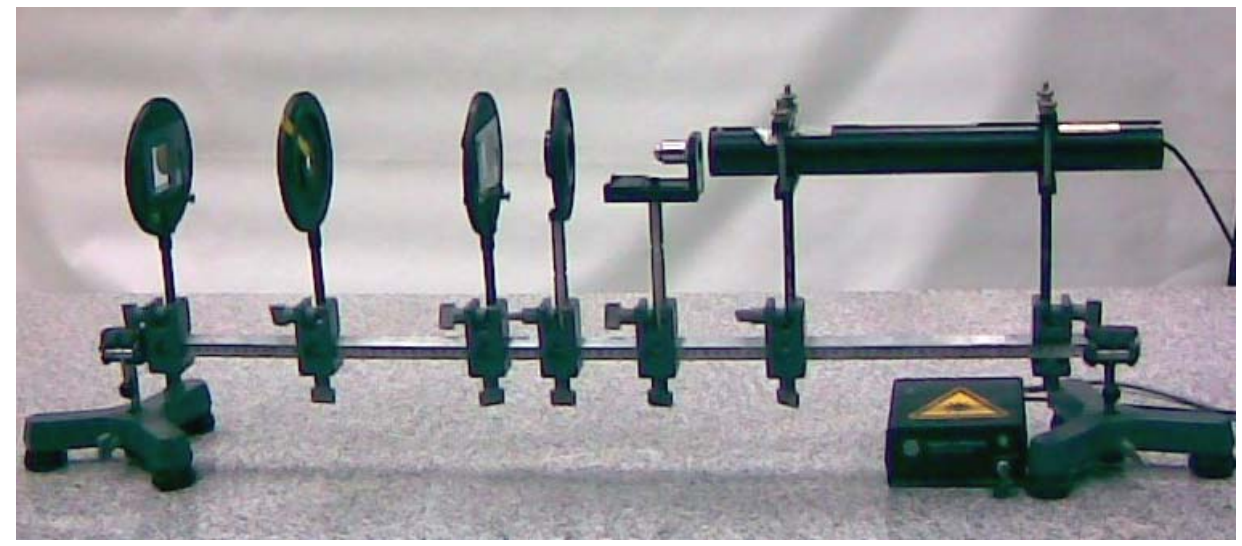

Fig. 3 Experimental set-up for recording speckle pattern

Interference of Huygen's wavelets gives rise to a granular pattern which is called "SPECKLE". The speckle pattern consists of random bright and dark spots. These spots are crowdie and acquire small sizes so that a high-resolution photographic plate must be used to record them. The diameter $\varepsilon$ of the smallest grains of the speckle in the plane of $\mathrm{H}$ is given by [2]:

$$
\varepsilon=\frac{\lambda}{\alpha}
$$

Where: $\alpha=\frac{a}{L}$.

The diameter $\varepsilon$ of the speckle grains depends only on the wavelength $\lambda$ and on the angle $\alpha$. Changing the distance $\mathrm{L}$ between $\mathrm{G}$ and $\mathrm{H}$ or the diameter of the aperture $\mathrm{T}$, the size of the grains of the speckle is actually changed [3-5]. In our experiments speckles were recorded using He-Ne laser with $\lambda=632.8$ $\mathrm{nm}$ and $\alpha=1 / 10(\mathrm{a}=1.5 \mathrm{~cm}$ and $\mathrm{L}=15 \mathrm{~cm})$ so that the grains had diameters of the order of $6 \mu \mathrm{m}$. Highresolution photographic plate of the type Agfa Gevart 10E75 or of the type Kodak 649f was used to record speckle pattern so that they served as excellent diffusers. It may be noted that observing point sources through these diffusers a uniformly extended halos are observed around the source. The halo represents the Fourier transform of the diffuser, in the focal plane of the eye lens.

\subsection{Production of single-exposure Gabbor hologram:}

The production and recording of single-exposure Gabbor holograms can be performed using the set-up represented in fig.4. The arrangement consists of a He-Ne laser, a diffuser D (which is obtained in fig.3), and a jig containing photographic plate $\mathrm{H}$ which can be oriented and displaced using two perpendicular micrometers.

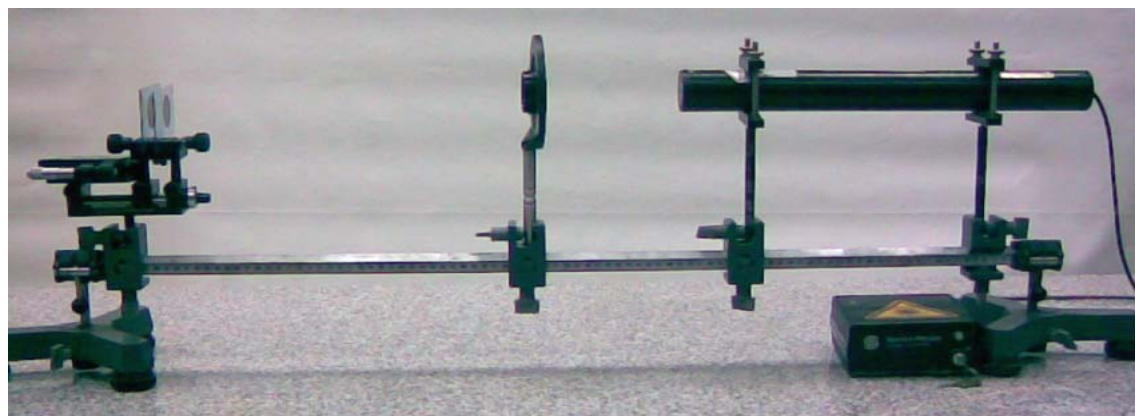

Fig. 4 Experimental set-up for recording Gabbor hologram.

The holographic plate $\mathrm{H}$ is placed at a distance $(\mathrm{L}=0.014 \mathrm{~cm})$ from the diffuser $\mathrm{D}$. Then this process is repeated for $(\mathrm{L}=0.056 \mathrm{~cm}, \mathrm{~L}=0.08 \mathrm{~cm}, \mathrm{~L}=0.093 \mathrm{~cm}$, and $\mathrm{L}=0.13 \mathrm{~cm})$ to obtain five Gabor holograms (five diffusers). 


\subsection{Production of circular interference fringes from single-exposure Gabbor holograms:}

The observation and photographing of the interference rings due to Gabbor hologram can be performed by means of the experimental arrangement which is shown in fig.5. The rings are localized in the focal plane of a converging lens $\mathrm{S}$. The incident light beams, from light source are collimated by the lens combination $\mathrm{C}_{1}$ and $\mathrm{C}_{2}$ where pinhole $\mathrm{P}$ is used as a secondary point source. It may be noted that the incident collimated beam falls perpendicularly on the single-exposure Gabbor hologram $\mathrm{H}$, then the interference fringes are localized in the focal plane of a converging lens $\mathrm{S}$ where it captured using CCD camera (Model 8313-1000, COHU Company).

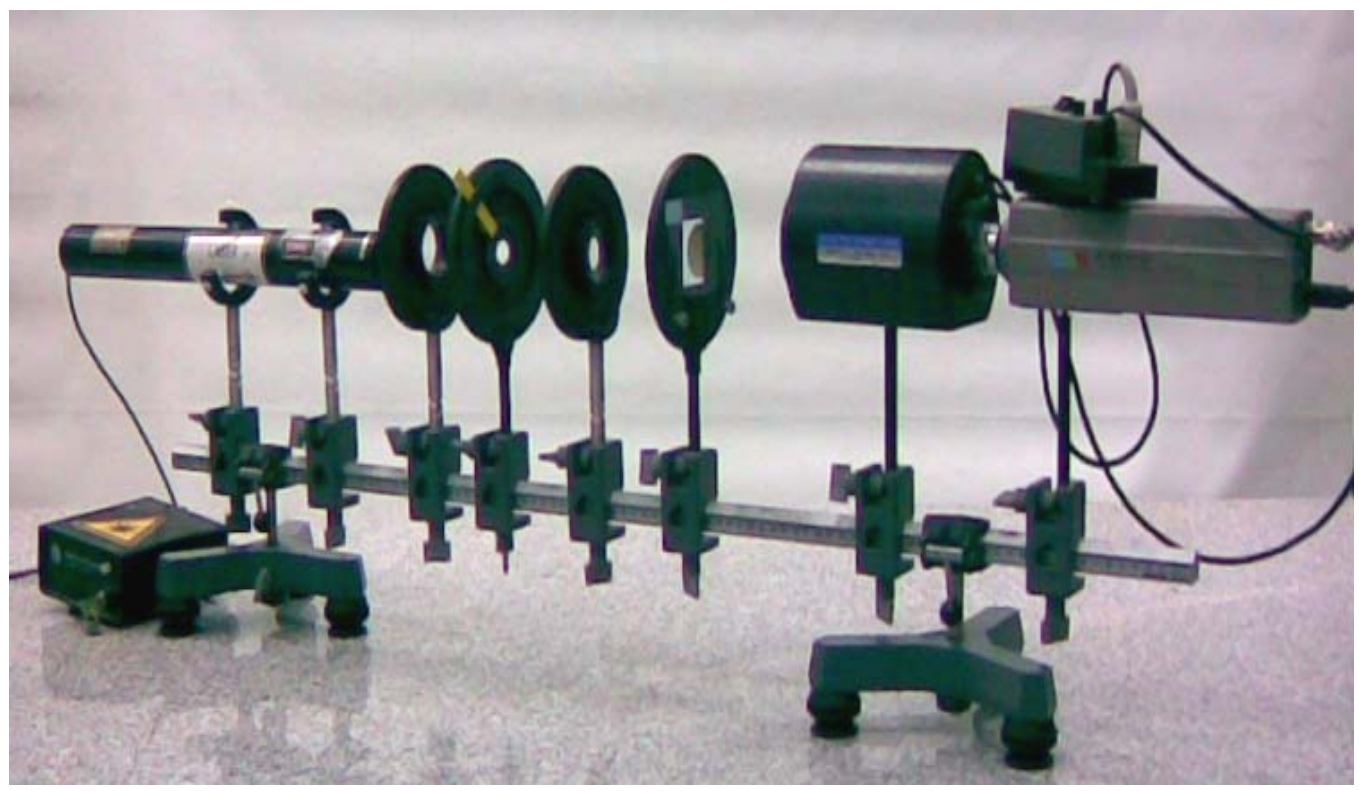

Fig. 5 Experimental set-up for recording the interference fringes due to Gabbor holograms.

These holograms are illuminated using different types of sources [He-Ne laser $(\lambda=632.8 \mathrm{~nm})$, diode laser $(\lambda=670 \mathrm{~nm})$, red LED, orange LED, yellow LED, green LED, blue LED] and the obtained interference patterns are shown in figs. (6-10).

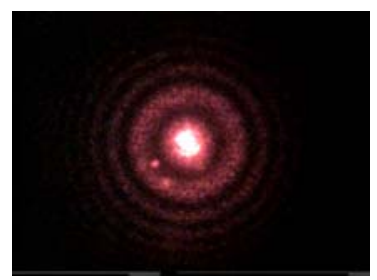

He-Ne laser

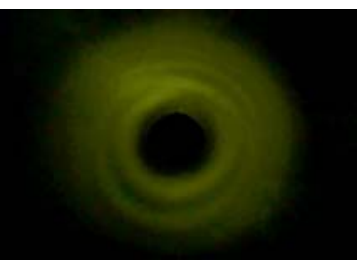

Green LED

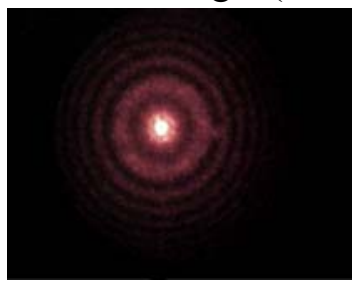

Diode laser

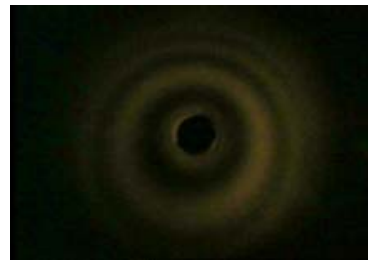

Yellow LED

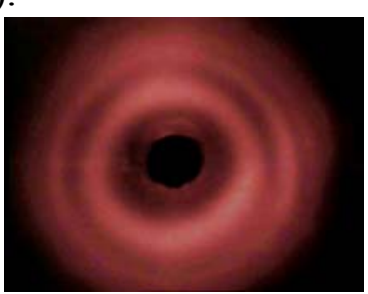

Red LED

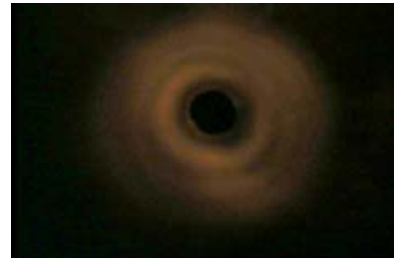

Orange LED

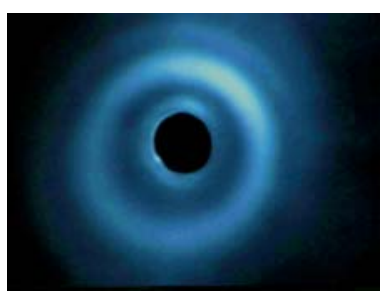

Blue LED

Fig. 6 Circular fringes due to single-exposure Gabor hologram of separation $\mathrm{L}=0.014 \mathrm{~cm}$ for different types of sources. 

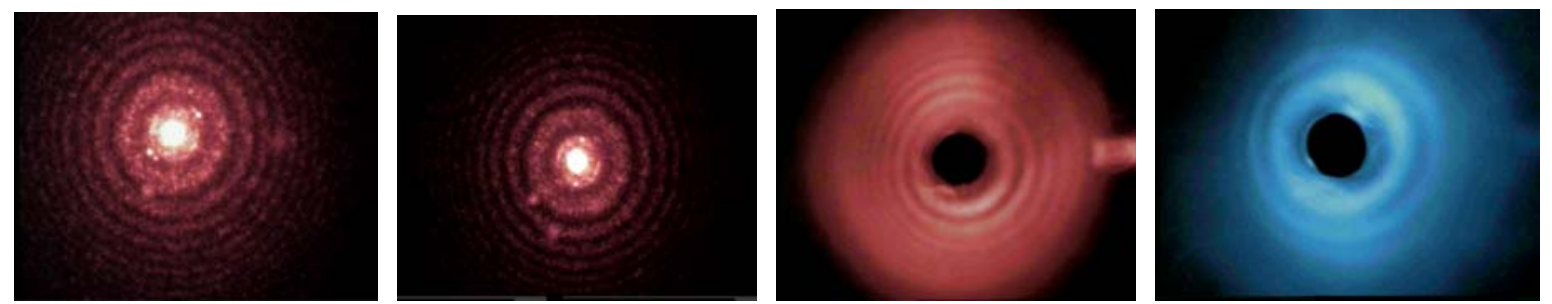

He-Ne laser

Diode laser

Red LED

Blue LED
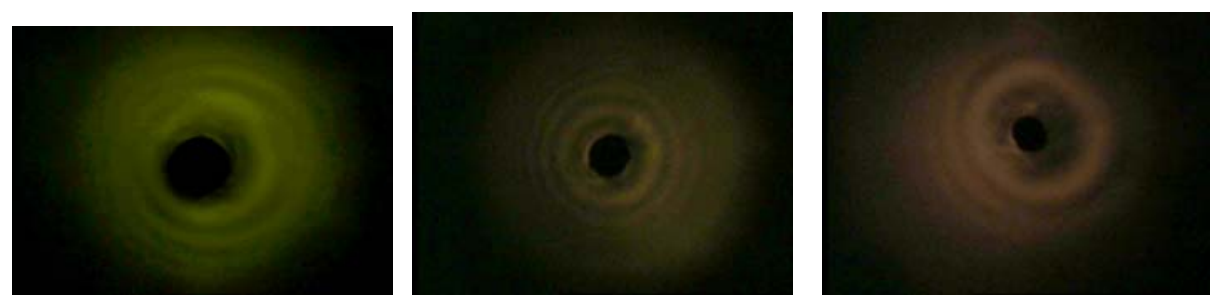

Green LED

Yellow LED

Orange LED

Fig. 7 Circular fringes due to single-exposure Gabor hologram of separation $\mathrm{L}=0.056 \mathrm{~cm}$ for different types of sources.

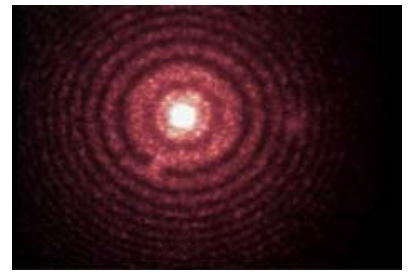

He-Ne laser

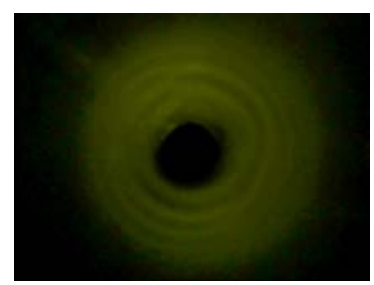

Green LED

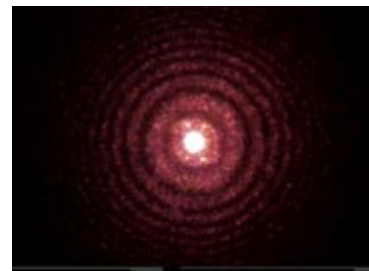

Diode laser

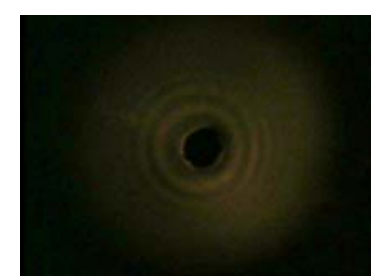

Yellow LED
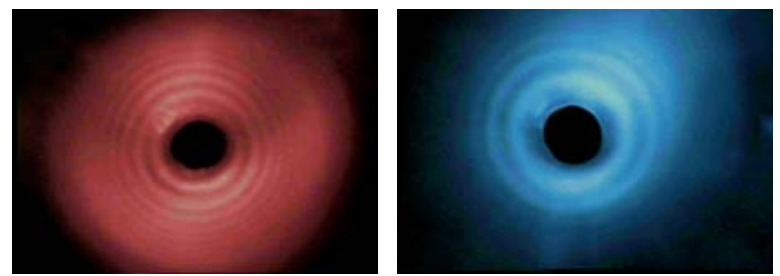

Red LED

Blue LED

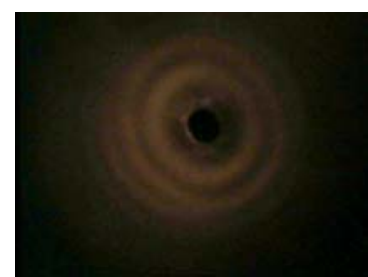

Orange LED

Fig. 8 Circular fringes due to single-exposure Gabor hologram of separation $\mathrm{L}=0.08 \mathrm{~cm}$ for different types of sources. 

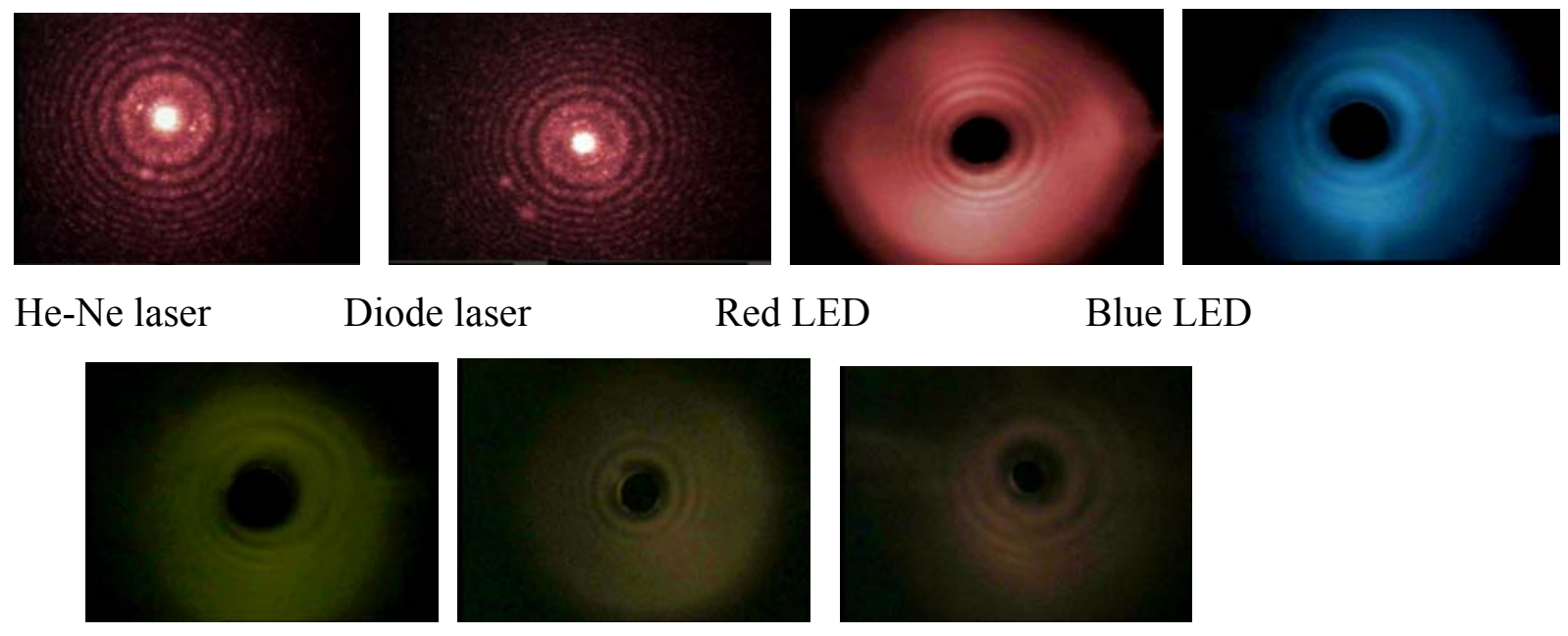

Green LED

Yellow LED

Red LED

Blue LED

Fig. 9 Circular fringes due to single-exposure Gabor hologram of separation $\mathrm{L}=0.093 \mathrm{~cm}$ for different types of sources.

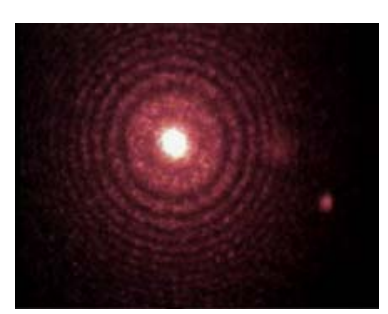

He-Ne laser

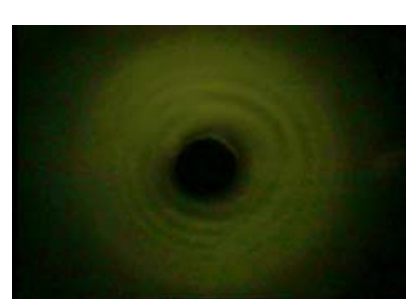

Green LED

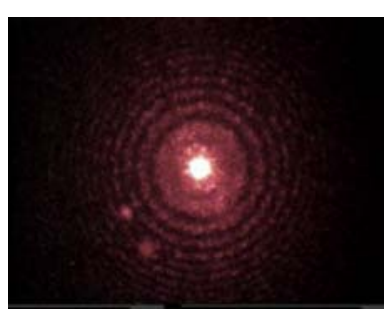

Diode laser

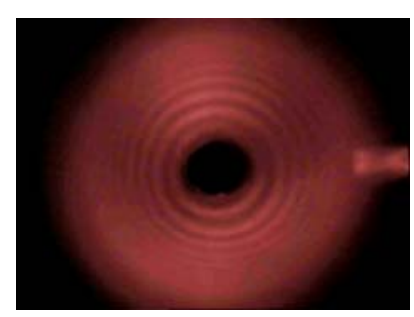

Red LED

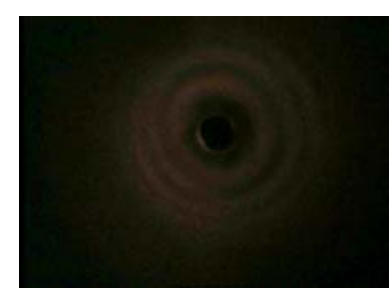

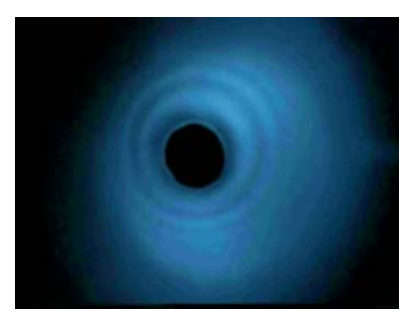

Blue LED

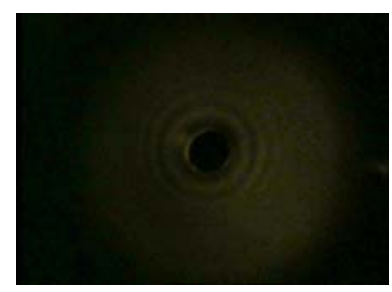

Yellow LED

Orange LED

Fig. 10 Circular fringes due to single-exposure Gabor hologram of separation $\mathrm{L}=0.13 \mathrm{~cm}$ for different types of sources.

\section{Data reduction:}

It may be noted that the ring diameters clearly depends on the wavelength $\lambda$ and the separation $\mathrm{L}$. If the squared radii $\mathrm{R}_{\mathrm{k}}{ }^{2}$ of the fringes are related to the order of appearance $\mathrm{k}$ a set of straight lines are obtained as shown in figs. (11-17) for a different sources that mentioned before. For each source, as the separation L is increased the slope of the straight lines decreases. Each group of these straight lines meets in the origin in the case of He-Ne laser and diode laser while have different slopes. But; for the case of colored LEDs the straight lines does not meet in the origin due to the fraction in order K using LEDs and due to the variation between the used light source for production and that for generating Gabor fringes (because; the Gabor holograms produced using He-Ne laser but now illuminated by LEDs). From these straight lines one can deduce the wavelengths from their slopes, which is equal to $\left(\lambda f^{2} / L\right)$. 
The wavelengths of the examined sources are calculated from the slopes of the straight lines (where $\mathrm{f}=58 \mathrm{~mm}$ for the case of laser sources, and $\mathrm{f}=150 \mathrm{~mm}$ for the case of LEDs) as shown in table (1).

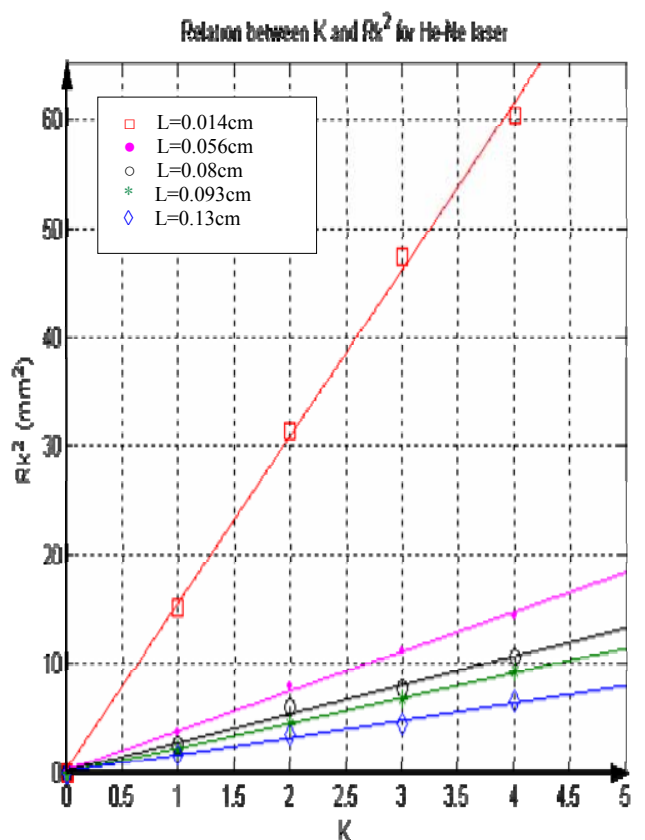

Fig. 11 Relation between the squared radii of the fringes and their order of interference, for He-Ne laser $(\lambda=632.8 \mathrm{~nm})$.

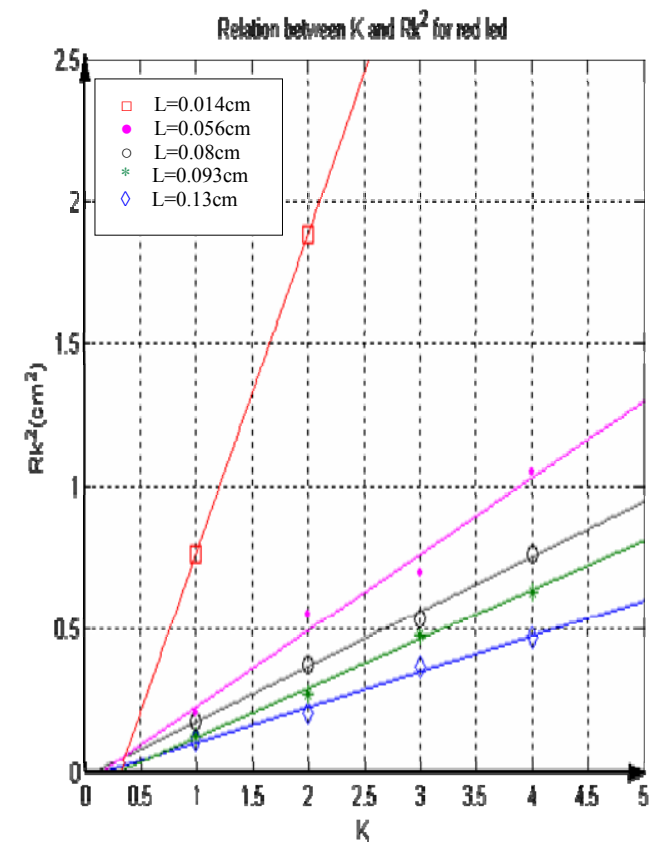

Fig. 13 Relation between the squared radii of the fringes and their order of interference, for red LED.

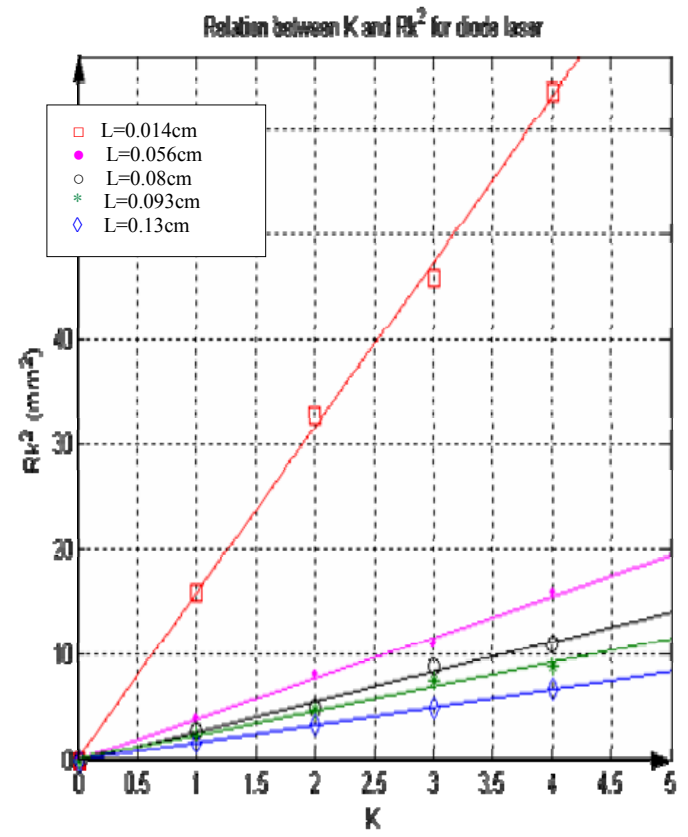

Fig. 12 Relation between the squared radii of the fringes and their order of interference, for diode laser $(\lambda=670 \mathrm{~nm})$.

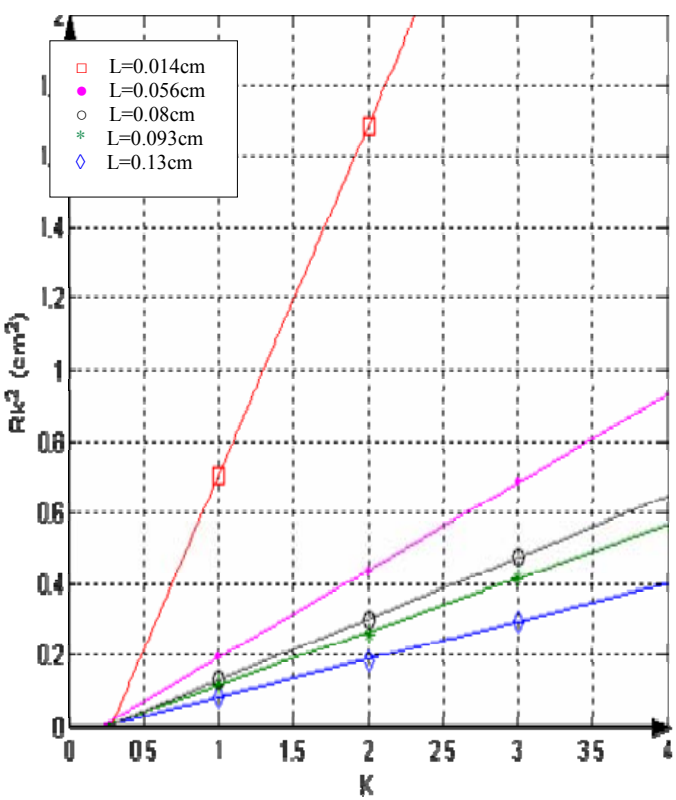

Fig. 14 Relation between the squared radii of the fringes and their order of interference, for orange LED. 


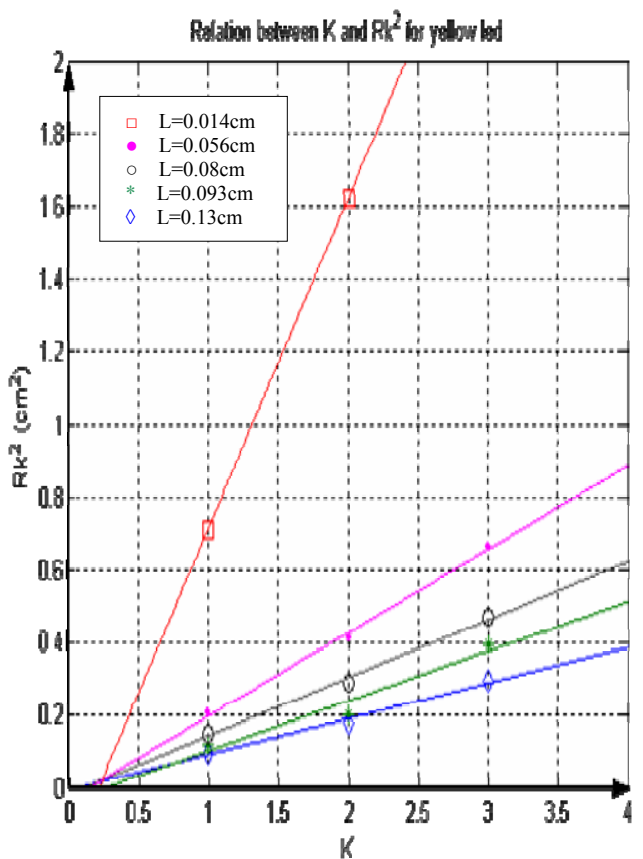

Fig. (15) Relation between the squared radii of the fringes and their order of interference, for yellow LED.

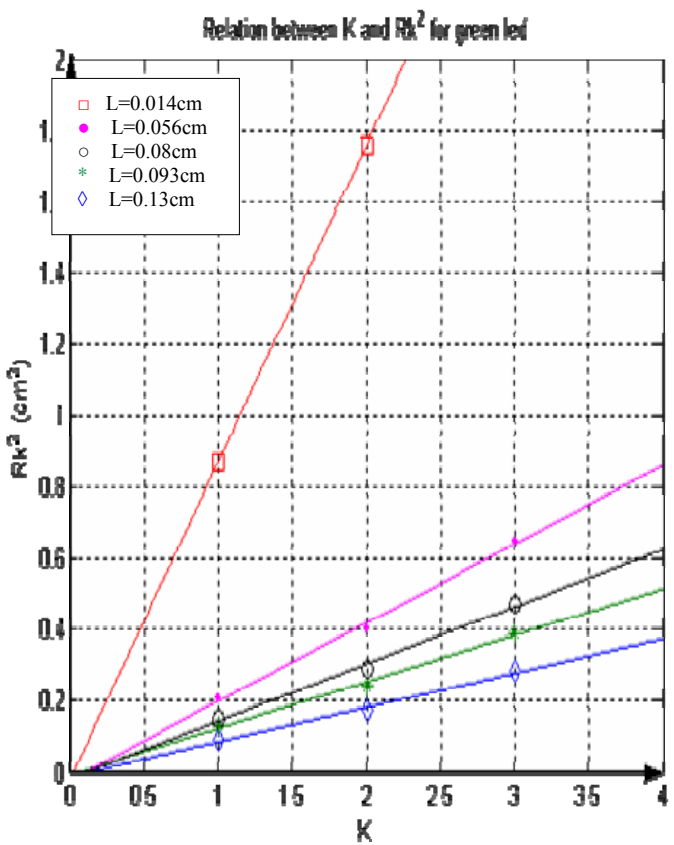

Fig. 16 Relation between the squared radii of the fringes and their order of interference, for green LED.

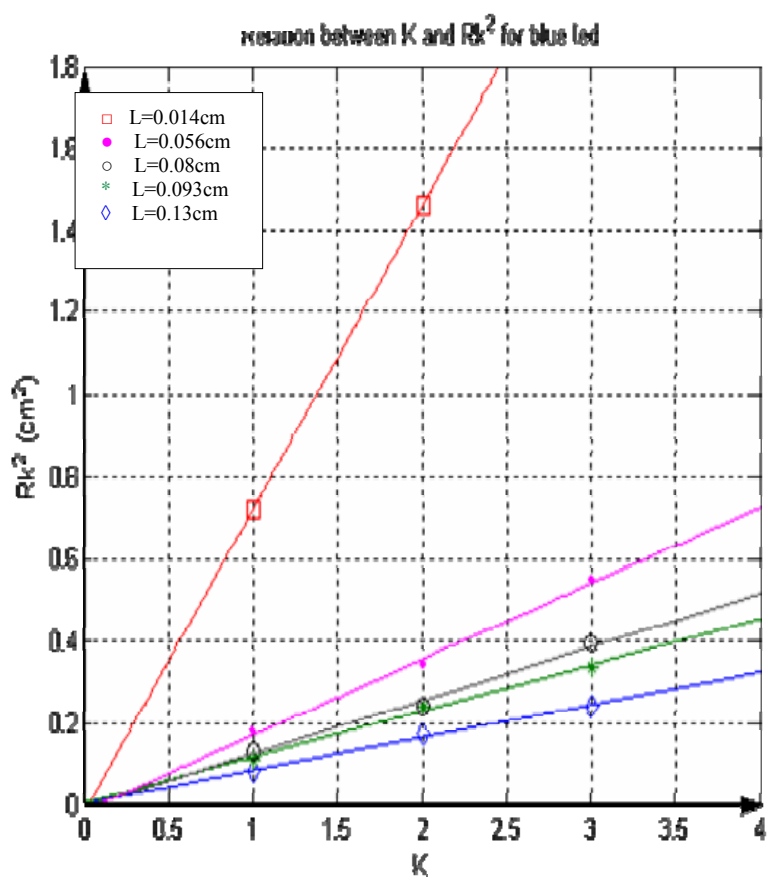

Fig. 17 Relation between the squared radii of the fringes and their order of interference, for blue LED. 
Table (1) the measured wavelengths form the $\left[K \& R_{k}{ }^{2}\right]$ relation.

\begin{tabular}{|l|l|l|l|l|l|l|l|}
\hline Source & $\begin{array}{l}\text { He-Ne } \\
\text { laser }\end{array}$ & $\begin{array}{l}\text { Diode } \\
\text { laser }\end{array}$ & $\begin{array}{l}\text { Red } \\
\text { LED }\end{array}$ & $\begin{array}{l}\text { Orange } \\
\text { LED }\end{array}$ & $\begin{array}{l}\text { Yellow } \\
\text { LED }\end{array}$ & $\begin{array}{l}\text { Green } \\
\text { LED }\end{array}$ & $\begin{array}{l}\text { Blue } \\
\text { LED }\end{array}$ \\
\hline $\begin{array}{l}\text { Wavelength of } \\
\text { standard } \\
\text { source }\end{array}$ & $632.8 \mathrm{~nm}$ & $670 \mathrm{~nm}$ & $\begin{array}{l}\text { Central } \\
\text { peak at } \\
682 \mathrm{~nm} \\
\text { and } \\
\text { BW=30 } \\
\text { nm }\end{array}$ & $\begin{array}{l}\text { Central } \\
\text { peak at } \\
597 \mathrm{~nm} \\
\text { and } \\
\text { BW=35 } \\
\mathrm{nm}\end{array}$ & $\begin{array}{l}\text { Central } \\
\text { peak at } \\
591 \mathrm{~nm} \\
\text { and } \\
\text { BW=12 } \\
\mathrm{nm}\end{array}$ & $\begin{array}{l}\text { Central } \\
\text { peak at } \\
566 \mathrm{~nm} \\
\text { and } \\
\text { BW=24 } \\
\mathrm{nm}\end{array}$ & $\begin{array}{l}\text { Central } \\
\text { peak at } \\
463 \mathrm{~nm} \\
\text { and } \\
\mathrm{BW}=34 \\
\mathrm{~nm}\end{array}$ \\
\hline $\begin{array}{l}\text { Measured } \\
\text { wavelength }\end{array}$ & $629.4 \mathrm{~nm}$ & $662 \mathrm{~nm}$ & $697 \mathrm{~nm}$ & $611 \mathrm{~nm}$ & $566.8 \mathrm{~nm}$ & $555.8 \mathrm{~nm}$ & $460 \mathrm{~nm}$ \\
\hline
\end{tabular}

Another set of straight lines is obtained by relating the reciprocal of the separation L and the difference of squared radii for different wavelengths. These straight lines have different slopes which are equal to $\left(\lambda \mathrm{f}^{2}\right)$. These relations are shown in figs.(18-19).

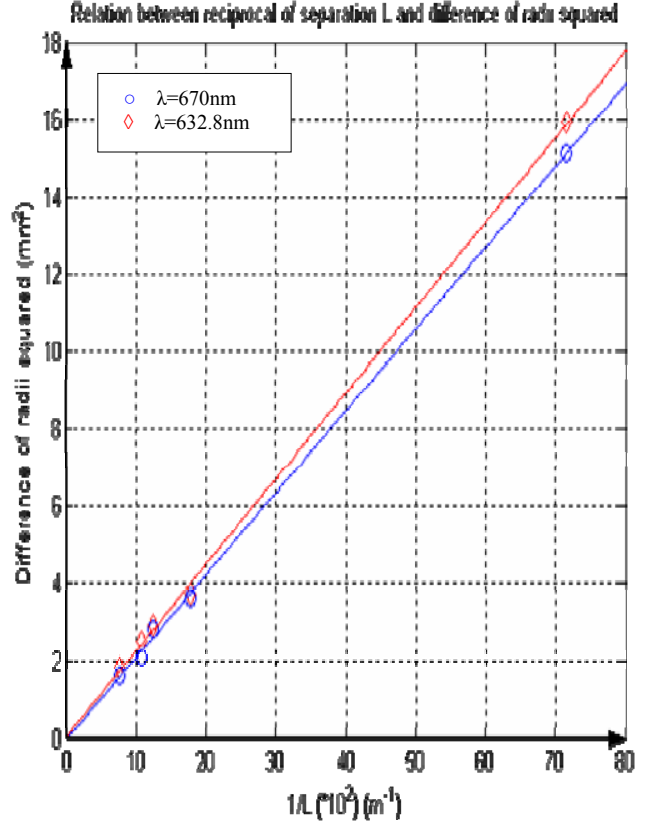

Fig. 18 Relation between the reciprocal of the separation $\mathrm{L}$ and the difference of squared radii for different wavelengths for laser sources.

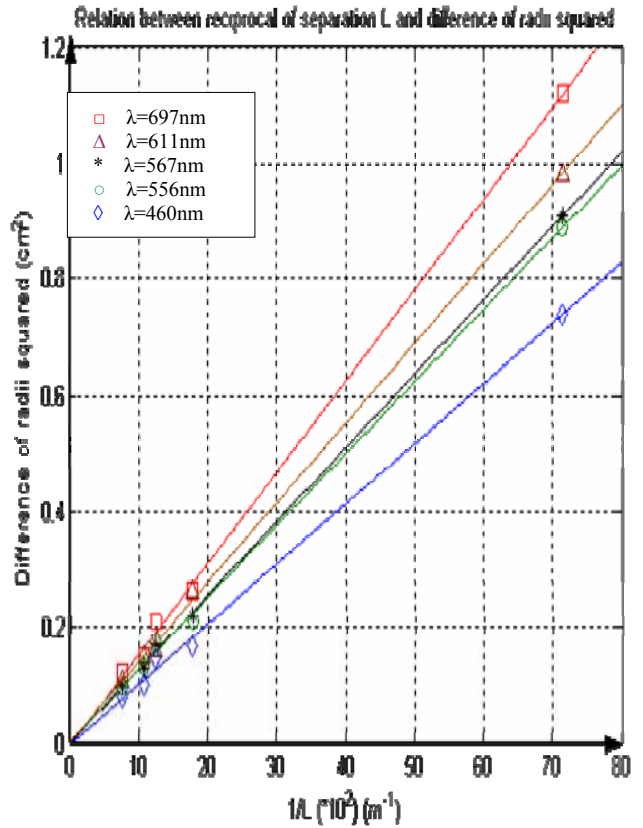

Fig. 19 Relation between the reciprocal of the separation $L$ and the difference of squared radii , for different wavelengths for LEDs. 
Table (2) the measured wavelengths form the $\left[(1 / L) \&\left(R_{k+1}{ }^{2} R_{k}{ }^{2}\right)\right]$ relation.

\begin{tabular}{|c|c|c|c|c|c|c|c|}
\hline Source & $\begin{array}{l}\text { He-Ne } \\
\text { laser }\end{array}$ & $\begin{array}{l}\text { Diode } \\
\text { laser }\end{array}$ & $\begin{array}{l}\text { Red } \\
\text { LED }\end{array}$ & $\begin{array}{l}\text { Orange } \\
\text { LED }\end{array}$ & $\begin{array}{l}\text { Yellow } \\
\text { LED }\end{array}$ & $\begin{array}{l}\text { Green } \\
\text { LED }\end{array}$ & $\begin{array}{l}\text { Blue } \\
\text { LED }\end{array}$ \\
\hline $\begin{array}{l}\text { Wavelength } \\
\text { of standard } \\
\text { source }\end{array}$ & $632.8 \mathrm{~nm}$ & $670 \mathrm{~nm}$ & $\begin{array}{l}\text { Central } \\
\text { peak at } \\
682 \mathrm{~nm} \\
\text { and } \\
\text { BW=30n } \\
m\end{array}$ & $\begin{array}{l}\text { Central } \\
\text { peak at } \\
597 \mathrm{~nm} \\
\text { and } \\
\mathrm{BW}=35 \\
\mathrm{~nm}\end{array}$ & $\begin{array}{l}\text { Central } \\
\text { peak at } \\
591 \mathrm{~nm} \\
\text { and } \\
\mathrm{BW}=12 \\
\mathrm{~nm}\end{array}$ & $\begin{array}{l}\text { Central } \\
\text { peak at } \\
566 \mathrm{~nm} \\
\text { and } \\
\mathrm{BW}=24 \mathrm{n} \\
\mathrm{m}\end{array}$ & $\begin{array}{l}\text { Central } \\
\text { peak at } \\
463 \mathrm{~nm} \\
\text { and } \\
\mathrm{BW}=34 \\
\mathrm{~nm}\end{array}$ \\
\hline $\begin{array}{l}\text { Slope of } \\
\text { straight line }\end{array}$ & $\begin{array}{l}2.123^{*} \\
10^{9}\end{array}$ & $\begin{array}{l}2.217^{*} \\
10^{9}\end{array}$ & $\begin{array}{l}15.75^{*} \\
10^{9}\end{array}$ & $\begin{array}{l}13.75^{*} \\
10^{9}\end{array}$ & $\begin{array}{l}12.75^{*} \\
10^{9}\end{array}$ & $\begin{array}{l}12.43^{*} \\
10^{9}\end{array}$ & $\begin{array}{l}10.39 * \\
10^{9}\end{array}$ \\
\hline $\begin{array}{l}\text { Measured } \\
\text { wavelength }\end{array}$ & $631.1 \mathrm{~nm}$ & $659 \mathrm{~nm}$ & $700 \mathrm{~nm}$ & $611 \mathrm{~nm}$ & $567 \mathrm{~nm}$ & $552.4 \mathrm{~nm}$ & $461.8 \mathrm{~nm}$ \\
\hline
\end{tabular}

Relating the difference of squared radii of the fringes to the measured wavelengths calculated previously in table (1) of the used light sources for different separations $(\mathrm{L}=0.014 \mathrm{~cm} \& \mathrm{~L}=0.056 \mathrm{~cm} \&$ $\mathrm{L}=0.08 \mathrm{~cm} \& \mathrm{~L}=0.093 \mathrm{~cm} \& \mathrm{~L}=0.13 \mathrm{~cm}$ ), another set of straight lines is obtained as shown in figs. (20$21)$. the slope of these straight lines is equal to $\left(\mathrm{f}^{2} / \mathrm{L}\right)$. Accordingly, the slope of these lines increases as the separation L decrease.

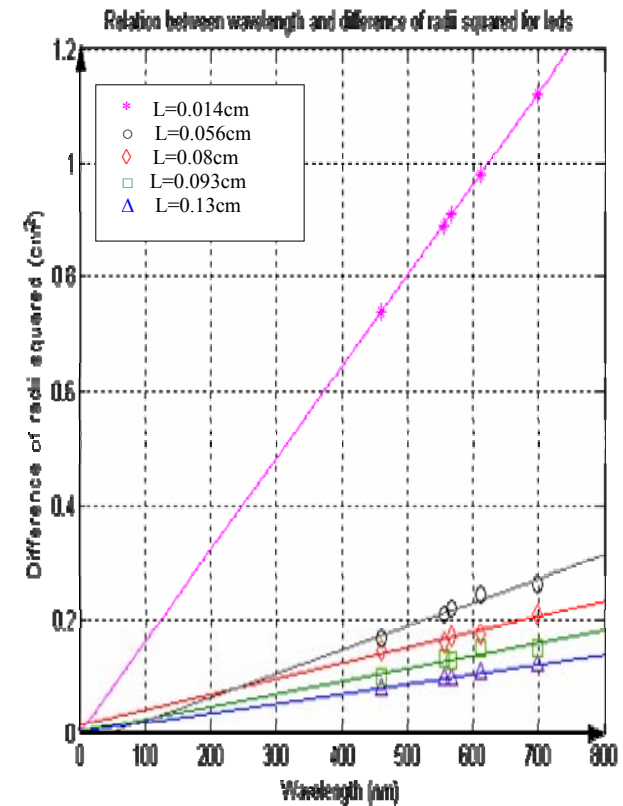

Fig. 20 Relation between the difference of squared radii and the wavelength of the incident light for LEDs.

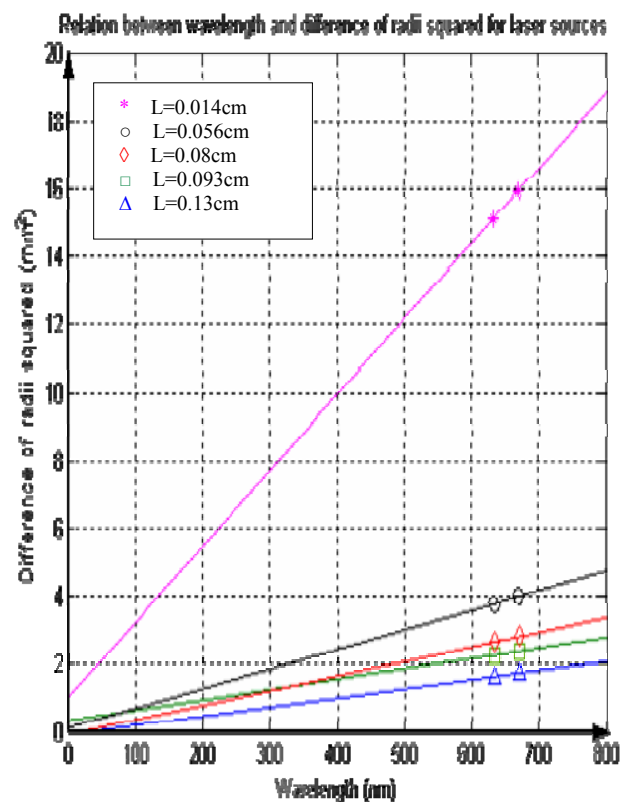

Fig. 21 Relation between the difference of squared radii and the wavelength of the incident light for laser sources.

For the case of laser sources the measured values of $\mathrm{L}$ are calculated as shown in table (3):

Table (3) the measured value of $L$ for laser sources form the $\left[\lambda \&\left(R_{k+1}{ }^{2} R_{k}{ }^{2}\right)\right]$ relation.

\begin{tabular}{|l|l|l|l|l|l|}
\hline Exact value of $\mathbf{L}$ & $0.014 \mathrm{~cm}$ & $0.056 \mathrm{~cm}$ & $0.08 \mathrm{~cm}$ & $0.093 \mathrm{~cm}$ & $0.13 \mathrm{~cm}$ \\
\hline Slope of straight line & 22.31 & 5.78 & 4.301 & 3.58 & 2.688 \\
\hline Measured value of $\mathbf{L}$ & $0.015 \mathrm{~cm}$ & $0.058 \mathrm{~cm}$ & $0.078 \mathrm{~cm}$ & $0.094 \mathrm{~cm}$ & $0.125 \mathrm{~cm}$ \\
\hline
\end{tabular}


For the case of LEDs and the measured values of $L$ are calculated as shown table (4):

Table (4) the measured value of $L$ for $L E D$ sources form the $\left[\lambda \&\left(R_{k+1^{-}}{ }^{2} R_{k}{ }^{2}\right)\right]$ relation.

\begin{tabular}{|l|l|l|l|l|l|}
\hline Exact value of $\mathbf{L}$ & $0.014 \mathrm{~cm}$ & $0.056 \mathrm{~cm}$ & $0.08 \mathrm{~cm}$ & $0.093 \mathrm{~cm}$ & $0.13 \mathrm{~cm}$ \\
\hline Slope of straight line & 166.67 & 41.33 & 27.17 & 22.2 & 16.95 \\
\hline Measured value of $\mathbf{L}$ & $0.0135 \mathrm{~cm}$ & $0.054 \mathrm{~cm}$ & $0.083 \mathrm{~cm}$ & $0.1 \mathrm{~cm}$ & $0.133 \mathrm{~cm}$ \\
\hline
\end{tabular}

\section{Conclusions}

Optical characteristics of the used surfaces were verified by the utilization of standard diffuse objects using the method of Gabbor holography. The Gabbor holograms were used to produce Gabbor circular fringes with different light sources (He-Ne laser, Diode laser, and different colored LEDs). The Gabbor fringes were used to display the relations between the fringes order and its radii. From these relations we have obtained the corrected values of the light sources wavelength as presented in tables (1-2).

The experimental verification leads to the conclusion that when using light source (laser diode of $\lambda=697 \mathrm{~nm}$ ) give the same performance of (a red LED with central peak at $\lambda=682 \mathrm{~nm}$ and $\mathrm{BW}=30 \mathrm{~nm}$ ), and (laser diode of $\lambda=611 \mathrm{~nm}$ ) give the same performance of (an orange LED with central peak at $\lambda=597 \mathrm{~nm}$ and $\mathrm{BW}=35 \mathrm{~nm}$ ), and (laser diode of $\lambda=567 \mathrm{~nm}$ ) give the same performance of (a yellow LED with central peak at $\lambda=591 \mathrm{~nm}$ and $B W=12 \mathrm{~nm}$ ), and (laser diode of $\lambda=556 \mathrm{~nm}$ ) give the same performance of (a green LED with central peak at $\lambda=566 \mathrm{~nm}$ and $\mathrm{BW}=24 \mathrm{~nm}$ ), and (laser diode of $\lambda=460 \mathrm{~nm}$ ) give the same performance of (a blue LED with central peak at $\lambda=463 \mathrm{~nm}$ and $\mathrm{BW}=34 \mathrm{~nm}$ ). This means that the electronic sensor can deliver the same accuracy of laser diodes when replacing it by commercial LEDs [6-10].

\section{References:}

[1] P.Hariharan, “Optical Holography”, Cambridge University New York, ch.2, p.11-13, 1984.

[2] M.Francon, J. Japan, Appl. Phys. 14, 1975. Proc. ICO Conf. Opt. Methods in Sci. and Ind. Meas. Tokyo.

[3] K. Doh, T. C. Poon, M. H. Wu, K. Shinoda, Y. Suzuki, "Twin-image elimination in optical scanning holography", Optics \& Laser Technology, 28, pp. 135-141, 1996.

[4] L. Marti-Lopez, "Effect of primary aberrations on transverse displacement of laser speckle patterns," Optics \& Laser Technology, 28, pp. 15-19, 1996.

[5] J. Fang, K. H. Laermann, "A carrier method of speckle-shearing interferometery for individualcomponent patterns of in-plane strain," Optics \& Laser Technology, 27, pp. 139-143, 1995.

[6] T. W. Ng, "The optical mouse as a two-dimensional displacement sensor", Sens. Actuators A, 116, pp. 205-208, 2003.

[7] K. M. Lee, D. Zhou, "A real time optical sensor for simultaneous measurement of the DOF motions,” IEEE/ASME Trans. Mech., 9, pp. 499-507, 2004.

[8] Umberto Minoni, Andrea Signorini, "Low-cost optical motion sensors: an experimental characterization," Elsevier B.V., 402-408, 2006.

[9] P. Popov, S. Pulov, V. Pulov, "A laser speckle pattern technique for designing an optical computer mouse," Optics \& Laser Technology, 42, pp. 21-26, 2004.

[10] Y. Ohno, "Spectral design considerations for white LED color rendering," Opt. Eng., 44, pp.11$13,2005$. 